\title{
SMEs High-Growth in Thailand
}

\author{
Dr.Terdsak Rojsurakitti \\ Rattana Bundit University
}

\begin{abstract}
This study investigated in the secondary data regards to SMEs High growth sectors of Hong Kong, Japan and Hungary. The result found that these 3 countries have been promoting SME sectors under the differentiation in structures and economics, so that, this study attempt to identify Key Performance Indicators (KPIs) and classified SME High Growth Sector in Thailand which are (1) Economic Growth (2) Value Added (3) Employment (4) Technological Intensiveness. The study also examined Policies that connected with the promotion of High Growth SMEs in Hong Kong, Japan and Hungary which based on Market Failure Theory and State Failure Theory. From analysis, Key Performance Indicators of SME high growth sectors in Thailand are (1) Food industry (2) Textile industry (3) Machinery industry (4) Rubber industry and products (5) Gems and jewelry industry (6) Plastics and packaging industry. Thus, Thai government should adopt successful schemes from best practices in order to expand Thai economic into ASEAN and global market.
\end{abstract}

Keywords: SMEs, Performance Indicators (KPIs), classified SME High Growth Sector, Economic Growth, Value Added, Employment, Technological Intensiveness

\section{INTRODUCTION}

Thai small and medium businesses are being urged to prepare themselves for growing competition, especially from the upcoming regional market integration. Thai government is looking for ways to help small and medium-sized enterprises (SMEs) maximize the benefits that will come from the regional integration, due to Asian Economic Community (AEC) will take place in 2015. SMEs are a significant mechanism for economic development in Thailand. The Thai government has recognized the importance of small and medium-sized firms to their economy since 1992 when an SME agenda was put into the National Economic and Social Plan for the first time. However, only after an economic crisis in 1997 when SMEs proved to be more resilient than larger enterprises did the Thai governments embark upon and seriously review and formulate a policy for SME development. In 1999, the Institute for Small and Medium Enterprises Development (ISMED) was established to promote the development of SMEs in Thailand. The problems facing Thai SMEs (data from ISMED, www.ismed.or.th) are as follows:

1. Limited access to financial resources

2. Lack of qualified human resources

3. Insufficient production or manufacturing technology

4. Insufficient marketing skills

5. Family-style management

6. Limited use of government support

7. Limited access to information

These problems highlight the need to support Thai SMEs to become more competitive as markets in Thailand and surrounding countries have become increasingly globalized. At 
present, about 30 percent of Thai enterprises rely on export markets (data from Department of Industrial Promotion).

As one of the fastest growing economic regions in the world, ASEAN's GDP in 2010 reached USD 1.85 trillion, or 3\% of global GDP, with total trade of over USD 2 trillion, comprising 6.8\% of world trade. Thailand is located at the heart of ASEAN and representing its second largest economy, thus, it is an ideal place for trade and investment. The country is a centre of transportation networks with a strong banking system, developed infrastructure, and skilled labor force. To leverage the country's strengths, the government will continue to execute proactive measures to ensure a favorable environment for AEC.

For Supporting Thai SMEs to achieve quality and sustainable growth, this study attempted to investigate best practices of Hong Kong, Japan and Hungry to identify KPIs for measuring high growth SMEs in Thailand. The purpose of this study is to identify SME sectors in various countries. The benefits of promoting high growth SMEs are generate economic growth, create value added, and create employment with high Quality and compensation. For example, in the UK, 4 percent of the start-up companies can generate employment more than 50 percent within 10 years (Storey, 1994) or in the U.S., 3 percent of the fastest-growing companies can create employment more than 70 percent between 1992 and 1996 (Birch et al., 1997).Also, GEM global report (Autio, 2005) suggests that entrepreneurs are inspired to create business which accounted for less than 10 percent of all new entrepreneurs which can create employment up to 80 percent.

\section{The definition of high-growth enterprises recommended is as follows:}

"All enterprises with average annualized growth greater than $20 \%$ per annum, over a three year period should be considered as high-growth enterprises. Growth can be measured by the number of employees or by turnover."

From the above definition, the study also found that the characteristics of High-Growth Enterprise are different from general enterprises in terms of the intention to utilize technology, and also the investment in time and money for training to develop their staffs, hire qualified employees (EIM, 2006). High Growth Enterprises can be defined in any size of the companies, young companies and also high proportion of employment in all types of businesses, not limited only high-technology business (Henreksson\& Johansson, 2010).

A variety of approaches can be considered as providing the basis for defining high-growth enterprises. Many studies, for example, have focused on indicators that define high-growth enterprises as the top Y\% of companies, for example Birch type measures, which marry absolute and relative changes in growth as a way of overcoming the small enterprise bias inherent in measuring enterprise growth rates.

$$
\text { 『Growth=(X】_t1-X_t0)X_t1/X_t0 }
$$

Where $x t$ is either employment, turnover or some other indicator of size in year t. Or the "Davis, Haltiwanger, Schuh'measure used by US statistical agencies for example, which measures growth on the following basis:

Growth $=\left(\left(X_{-} t 1-X_{-} t 0\right)\right) /\left(\left(X_{-} t 1+X_{-} t 0\right)\right) / 2$

This is the approach used in this study. Like the measures above, thresholds are selected by convention based largely on individual country studies/experiences. High-growth enterprises can be defined both in terms of employment (number of employees) and in terms of turnover. 
In order to study the phenomenon of high growth enterprises, it is recommended that both criteria are used.

\section{The purposes of this research are as following;}

1. To study / analysis secondary data and statistical information from Thailand and abroad countries to identify KPIs and classified SME High Growth Sector.

2. To collect the data regards to KPIs in order to analyze the opportunities and growth potential of SMEs high-growth enterprises.

3. To study the issues / barriers of SMEs High Growth Sector in Thailand and find solutions and appropriate government policies to support the growth of SME High-growth enterprises.

\section{The policies related to the promotion of the High Growth SMEs in many countries are as following;}

\section{Hong Kong}

Hong Kong is one of the freest economies in the world. While respecting the functions of a market economy, the Government should be appropriately proactive, and take a more positive role to facilitate the long term economic development of Hong Kong. In relation to innovation and technology, the Government will focus on the development of the highly competitive sectors of the industries in the light of Hong Kong's strengths. We will provide software and hardware support, foster co-operation among the Government, industry, academia and research sectors, forge closer collaboration with the Mainland, and inject additional resources where necessary.

1. Work with stakeholders to explore the development of intellectual property trading in Hong Kong

2. Encouraging more enterprises from the Mainland, Taiwan and the emerging markets including Southeast Asia, Russia, India, the Middle East and South America to invest in Hong Kong and helping our enterprises tap the business opportunities in these markets; and strengthening aftercare services and support to those enterprises already established here to encourage them to upgrade their presence.

3. Continuing to support Hong Kong enterprises in the development and promotion of Hong Kong brands to enable them to better compete in the Mainland and overseas markets.

4. Continuing to support Hong Kong enterprises (in particular SMEs) through measures including various funding schemes

5. Reviewing the Patent System to ensure that it continues to meet present-day circumstances and is commensurate with our efforts to develop Hong Kong into a regional innovation and technology hub.

6. Continuing to engage stakeholders for strengthening copyright protection in the digital environment.

7. Continuing to promote awareness of IP rights in the business sector, and to assist business, in particular SMEs, to achieve compliance with IP rules.

8. Study how best to promote realization of research and development (R\&D) results and collaboration with the Mainland through supporting the work of the stakeholders. 
9. Supporting the R\&D of SMEs through the Small Entrepreneur Research Assistance Programme (SERAP)

10. Capitalizing on the opportunities presented by the National 12th Five-Year Plan in science and technology collaboration with the Mainland.

11. Working closely with the Hong Kong Science and Technology Parks Corporation (HKSTPC) on the development of Hong Kong Science Park Phase 3, the revitalization of industrial estates (IEs) and the feasibility study on the proposed extension of Yuen Long Industrial Estate (YLIE).

12. Promoting applied $R \& D$ and technology transfer to the industry through the $R \& D$ Centres (including ASTRI) and the ITF.

13. Reviewing and refining the R\&D Cash Rebate Scheme to reinforce research culture among business enterprises and encourage them to establish stronger partnership with designated local public research institutions.

14. Working closely with the Hong Kong Council for Testing and Certification (HKCTC) to implement the three-year market-driven industry development plan proposed by HKCTC in 2010.

15. Organizing a wide range of promotional activities including the InnoTech Month (ITM) during October 2012 to enhance the community's awareness of I\&T.

Under the structure of Hong Kong government, there are 2 institutions that responsible of promoting High-Growth SMEs sector which are:

\section{Hong Kong Applied Science and Technology Research Institute (ASTRI)}

ASTRI has been delivering world-class technologies and customer-focused R\&D which cater to the needs of the industry. Our R\&D efforts traverse five main technological areas:

- Information and Communication Technologies.

- Electronics for consumers and businesses.

- Integrated Circuit

- Materials Technology and packaging

- medical Electronics

2. Hong Kong Science \& Technology Parks (HKSTP) Incubation Program

The Hong Kong Science and Technology Parks (HKSTP) is a result of mergers between several incubation centers and technology parks in Hong Kong which founded in 2001 and is sponsored by the Hong Kong government. The incubation center targets firms in the start-up and early growth phases, and the science park caters to firms that are already in the expansion or maturity stages of development. HKSTP focuses in 5 key industries including;

1. Biotechnology

2. Electronics

3. Green Technology

4. Information Technology \& Telecommunications

5. Precision Engineering

HKSTP has been successful in supporting the growth of young firms as well as in creating clusters of technology firms. Of the incubates, about $10-15 \%$ tends to do quite well. 


\section{Japan}

The policy framework conditions in support of start-ups have emerged since the early 1960s when the Small and Medium Business Investment and Consultation Company were established in Tokyo, Osaka and Nagoya. In 2000, university venture firms were promoted through the Law to Strengthen Industrial Technology. Policy measures have been complemented by support programs such as the Small Business Innovation Research (SBIR) program, the creation of the JASDAQ and Mothers stock markets, the promotion of venture business laboratories at university sites - in order to host early stage university venture firms - and the promotion of venture funds. More recently, there have been changes to how angel taxation is calculated. Japan is now taking steps to activate its venture capital market. First the Tokyo Stock Exchange, on November 1999, launched a junior stock exchange with the acronym "MOTHERS (Market of die High-Growth and Emerging Stocks)" for new companies in need of capital. According to Mitsuhide Yamaguchi, the president \& CEO of Tokyo Stock Exchange, the primary purpose of MOTHERS is to revitalize the Japanese economy by promoting new industries that will play a major role for the coming generation. Second, JASDAQ, the Japanese OTC market reformed its listing requirements on December 1998. With the new system, JASDAQ classifies companies listed into two tiers where tier 1 keeps the old requirements, whereas tier 2's listing requirements are more relaxed. Third, NASDAQ Japan was launched in July 2000. Finally, several local stock exchanges such as Fukuoka and Osaka Stock Exchanges also opened (in2000, and in 1998 respectively) stock markets (as sub-exchanges) for emerging businesses. Japan is often characterized as an economy of big corporations and conglomerates like NEC or Sony. In reality, the fabric of the Japanese economy is woven not with these large conglomerates but primarily with small and medium sized enterprises (SMEs). Facing increasingly internationalized production structures, traditional relations between large corporations and small subcontractors are unraveling.

- Dramatic improvement in Japan's attractiveness as a business base to succeed in international competition

- Strategic fields to drive new growth

- Invigoration of regional economies and SMEs

- Implementation of "open" economic and industrial policies from integrated internal and external perspectives

- R\&D for "value-creating-technology" and promotion of international standardization strategy

- IT as the basis for industrial and social advances

- Selection and concentration of projects through the strict scrutinizing of public projects and government project reviews and the lateral application of their results

The important policy initiatives on SMEs in Japan can be outlined as followed;

\section{Japan's New Growth Strategy}

Japan's New Growth Strategy aimed at tackling the country's problems in industrial structure which faced the problems from overreliance on specific industries and scarcity of resource in the economy; industry's delays in conversion of business strategy whereby the technological breakthrough could not effectively been convert to successful businesses; and Japan's loss of attractiveness as a business base, which was especially due to problems in the tax system and lack of excellent international talent. The New Growth Strategy aimed to;

\section{Small and Medium Enterprise Charter}

The major focus areas of Small and Medium Enterprise Charter are to;

- Supporting SMEs as a source of economic vitality, to make full use of their capabilities 
- Encouraging SMEs to start up new businesses

- Encouraging the challenges of SMEs to advance into and develop new markets with their creativity and ingenuity

- Enhancing fairness in markets

- $\quad$ Providing the safety net for worry-free business operations of SMEs

\section{Science and Technology Basic Policy The plan emphasized in;}

- Promotion of Green Innovation

- Promotion of Life Innovation

- System reform for promoting Science, Technology, and Innovation (STI)

4. Law on Special Measures for Industrial Revitalization and Innovation:

The amendment aimed at tackling the economic problems of difficulties due to the economic melt-down, financial crisis and increasing resource prices in 2008, thus the amendment was to provide the law with necessary measures to facilitate investment for saving energy and support for smooth financing with following strategies;

- Strategy to facilitate the founding of company, increasing capital, Merger \& Acquisition (M\&A), and business transfer

- Equipment investment

- Business succession(Ministry of Economy, Trade, and Industry, 2011)

\section{Hungary}

The Ministry of Economy and Transport (since 2008, the Ministry of National Development and Economy) launched its ambitious programme entitled "Tuned to Business" in late 2006. This complex programme is primarily aimed at creating a more favourable business climate by reducing administrative and financial burdens and simplifying the regulatory framework for businesses in general, but the initiated steps are especially vital for innovative start-ups and High-Growth SMEs.

Furthermore, the Ministry of Economy and Transport has launched a measure "Fostering startup entrepreneurial activities" which targets start-up companies and, as one of its key target groups, technology-intensive RTDI-active spin-offs from higher education and public research institutes. It aims to disseminate knowledge pertaining to entrepreneurial culture, management skills, business planning, application systems and market-oriented ICT skills. To this end, the scheme supports the development of curricula and consultancy services to develop the vital entrepreneurship skills.

Studies of the Hungarian NIS and all major policy documents identify the insufficiency of available (early stage) venture capital as one of the key factors hindering the development of innovative, high-growth SMEs. Measures addressing this challenge include the following:

- The Corvinus Group

- The "Specific Investment Equity Guarantee" scheme of the START Equity Guarantee

- The Information Technology Venture Capital Fund

\section{RESEARCH QUESTIONS}

1. What are Key Performance Indicators (KPIs) to identify SME High Growth Sectors in Thailand?

2. KPIs can be used to analyze the opportunities and potential growth of SMEs in Thailand? 


\section{RESEARCH METHODOLOGY}

This study investigated in the best practices of Hong Kong, Japan and Hungary towards SME High-growth sectors to determine Key Performance Indicators of high growth and high value enterprises in Thai SME sectors. Also, expose the selection and ways to promote high growth SMEs in order to determine the issues / barriers of SME's High Growth Sector in Thailand and find out the appropriate policies to promote SMEs High Growth Sector in Thailand by adopting successful schemes of best practices which are Hong Kong, Japan and Hungary.

This study used secondary data towards policies that associated with the promotion of SMEs high growth sectors and Policy Delivery Mechanism of 3 countries which are Hong Kong, Japan and Hungary.

a. The details of the schemes.

b. Analyze KPIs of best practices to classify SMEs high growth enterprises in Thailand.

c. Promotion of SMEs High Growth Sector.

\section{DATA ANALYSIS}

- To Analyze Key Performance Indicators (KPIs) in order to benchmark high growth and high value SMEs in Hong Kong, Japan and Hungary under various circumstances and economic structure for investigating KPIs for SME high growth sectors in Thailand.

- To adopt successful schemes of 3 countries (Hong Kong, Japan and Hungary) in order to apply the appropriate approach to promote SMEs High Growth in Thailand

\section{RESULTS}

This study examined the secondary data towards Policies that connected with the promotion of High Growth SMEs in Hong Kong, Japan and Hungary which based on the following theories;

1. Market Failure Theory; the characteristics of Free Market cannot optimize the economic system. Thus, government is supposed to promote the High-Growth SMEs.

- Externalities: such as the introduction of products, services, and new business processes which promote consumer welfare for conveying to other business sectors and leading to External Economies of Scale.

- Imperfect Competition: large companies can create competitive barriers which leading to unfair pricing. Thus, Government needs to promote SMEs.

- Imperfect Information: the problem to access essential information such as financial data (Murray, Hyytinen\&Maula 2009).

2. State Failure Theory; the failure of the economic policy that influenced by the lobbying of big companies which results in an inefficient of resources distribution (Policy Brief in INNO-Grips, 2011).

3. To indicate Key Performance Indicators of Thai SME high growth sectors, this study examined successful schemes of Hong Kong, Japan and Hungary in order to apply appropriate approaches in Thailand. From analysis, the following are Key Performance Indicators of Thai SME high growth sectors;

1. Economic Growth

2. Value Added

3. Employment

4. Technological Intensiveness

From KPIs that mentioned above, this study determined SMEs High growth in Thailand into 6 sectors as following;

1. Food industry 

2. Textile industry
3. Machinery industry
4. Rubber industry and products
5. Gems and jewelry industry
6. Plastics and packaging industry

\section{CONCLUSION}

This study investigates in best practices regards to SMEs High growth sectors of Hong Kong, Japan and Hungary. The result found that these 3 countries have been promoting SME sectors under the differentiation in structures and economics. To indicate Key Performance Indicators of Thai SME high growth sectors, this study examined successful schemes of Hong Kong, Japan and Hungary in order to apply appropriate approaches in Thailand. For Instance, promote the Investment in Thailand by encouraging more enterprises from the Mainland, India and other countries to invest in Thailand and also help those enterprises tap the business opportunities in the markets. Also, promote Science and Technology sector in Thailand by adopt from ASTRI scheme of Hong Kong which delivering world-class technologies and customer-focused R\&D which cater to the needs of the industry and also Science and Technology Basic Plan of Japan which aimed to provide basic policies for comprehensive and systematic promotion. Moreover, the government of Thailand can support SME sectors by providing funds for start-ups businesses in terms of creating a more favourable business climate by reducing administrative and financial burdens and simplifying the regulatory framework for businesses in general, but the initiated steps are especially vital for innovative start-ups and High-Growth SMEs. From analysis, the following are Key Performance Indicators of Thai SME high growth sectors; 1.Economic Growth 2. Value Added 3.Employment 4.Technological Intensiveness. In addition, from KPIs that mentioned above, this study determined SMEs High growth in Thailand into 6 sectors as following; 1.Food industry 2.Textile industry 3.Machinery industry 4.Rubber industry and products 5.Gems and jewelry industry 6.Plastics and packaging industry

\section{RECOMMENDATION TO THAI SMES}

To solve the problem of the disruption of the growth in Thailand industries due to the rise of minimum wage of workers, the high growth rates enterprises need to be adapted to conform the changes in terms of searching new markets, attempting to expand its market share to offset expenses, such as reduced the rate of employment and change production to lower labor costs countries, to modify strategies for various industries by utilizing technology and innovationdriven economy instead of labors. For example, Japan's New Growth Strategy of Japan aimed at tackling the country's problems in industrial structure which faced the problems from overreliance on specific industries and scarcity of resource in the economy; industry's delays in conversion of business strategy whereby the technological breakthrough could not effectively been convert to successful businesses in order to expand Thai economic into ASEAN and global market.

\section{References}

Anonymous, (2000). "Bencha Toshi Nihon No Kankyo Totomou [The Economical Environment Has been Arranged for Venture Investment]" Nihon Keizai Shinbun [Japan Economic Newspaper] February 7th, 15.

Anonymous, (2000). "Fukusho, Bencha Muke Shin Shijo [A New Market for Venture Business in Fukuoka Stock Exchange]" The Nikkei Financial Daily February 7th, 7.

Anonymous, (2000). "Nisshokyoshijo Ga Dam Michi [The Way for the Japanese Stock Market to Go]" The Nikkei Financial Daily February 7 th, 12.

Arunee T,(2007), "International Entrepreneurship Activities among Thai"UMI Microform number 3273672, by ProQuest Information and Learning Company,P15 
ASTRI - Home About ASTRI .(2013).ASTRI. Retrieved June 28, 2013, from

http://www.astri.org/main/index.php?contentnamespace=about_astri:company_profile

Autio, E. (2005). GEM 2005 Report on High-Expectation Entrepreneurship. London: Global Entrepreneurship Research Association.

Birch, D., Haggerty, A.,\& Parsons, W. (1997). Who's Creating Jobs? Cambridge, MA: Cognetics.

EIM ,(2006),."Entrepreneurship in the Netherlands. High-growth enterprises; running fast but still keeping control", EIM Business and Policy Research.

Farsang, A., \& Watt, A.,(2013)"National report on the Hungarian Energy regime”D 13 from the BARENERGY project.

Henrekson M, Johansson D,(2010), “Gazelles as job creators: a survey and interpretation of the evidence”, Small Business Economics p.35:227-244.

High-Growth Enterprises.(n.d.),(2013)" Eurostat - OECD Manual on Business Demography Statistics"[Retrieved July 28, 2013], from www.oecd.org/industry/business-stats/39974588.

Hong Kong Science \& Technology Parks - Mr. Andrew Young Meng-cheung,2013" Hong Kong Science \& Technology Parks - Homepage" Retrieved June 28, 2013, from http://www.hkstp.org/en-US/about-us/DirectorsOrganisation/Management-Team/Mr-Andrew-Young-Meng-cheung.aspx

Institute for Small Medium Enterprise Development, http://www.ismed.or.th

Industrial Marketing Management Volume 26, Issue 2, March 1997, Pages 101-113

Kathryn C. Ibata-Arens ,(2001) "The Politics of Innovations: High Technology Small Medium Sized Enterprise in Japan" UMI Number 3012012,P.3

JASDAQ, (1999). uToroku Seido No Gauyo [The Listing Requirements]" http://www.iasdaQ.co.fD/web/JOMarketnsf/flmainSet E 